\title{
ESTUDIO DE CARACTERES PRODUCTIVOS Y REPRODUCTIVOS DEL OVINO PELIBUEY
}

\author{
Cruz Sisniegas Frank (*) \\ López Flores Raúl $\left(^{* *}\right)$
}

\section{RESUMEN}

El estudio se efectuó entre agosto de 1987 y agosto de 1990, en virtud de un convenio con la Corporación Departamental de Desarrollo de Madre de Dios, la que en 1987 realizó la importación de 300 cabezas de ganado ovino Pelibuey, procedentes de la República de Cuba.

El hato inicial estuvo constituido por 32 animales, de los cuales 30 eran hembras y 02 machos. Se registraron los caracteres reproductivos y productivos siguientes:

Reproductivos: Fertilidad, duración de gestación, intervalo entre partos, tamaño de carnada, prolificidad, mortalidad, etc.

Productivos: Peso al nacimiento, destete al año, ganancia de peso diario, peso y edad a la madurez sexual, edad a la primera parición, etc.

Los objetivos principales del estudio fueron determinar los índices productivos y reproductivos de los ovinos y, en base a ello, determinar una tecnología de manejo adecuado a las condiciones de M adre de Dios.

Palabras claves: $\quad-$ Caracteres productivos y reproductivos

- Pelibuey

\section{INTRODUCCION}

El ovino Pelibuey, en su lugar de origen, Cuba, conforma una de las poblaciones más grandes de ovino de pelo existentes en la zona del Caribe, siendo su hábitat natural el clima tropical seco; sin embargo, al introducirse al Perú, las crianzas se han orientado a las características de la amazonía peruana, habiéndose adaptado perfectamente a su clima tropical húmedo. En el Perú se han venido conduciendo diferentes programas de promoción, desarrollo e investigación en ovinos, como el Black Belly de Barbados, Pelibuey de Cuba y Santa Inés de Brasil. 
El presente proyecto se originó por el deseo de la Corporación de Desarrollo de Madre de Dios (CORDEMAD), de conocer la adaptación del ovino Pelibuey cubano al clima tropical húmedo; por ello, la CORDEMAD decidió encargar a la Oficina Filial del IIAP en Madre de Dios, el desarrollo de un proyecto de investigación y crianza de ovinos de pelo. En este trabajo se presentan algunos de los parámetros productivos y reproductivos más importantes del ganado ovino Pelibuey, obtenido en el período A gosto 1987 / A gosto 1990.

\section{MATERIALES Y METODOS}

El estudio se realizó entre agosto de 1987 y agosto de 1990, en un pastizal de 4.7 Ha., cedido por el CEDEGA-CORDEMAD; el piso forrajero estaba constituido principalmente por Brachiaria decumbens $(3.7 \mathrm{Ha}$ ) y pasto común $(1 \mathrm{Ha})$.

El hato inicial estuvo constituido por 32 animales, 30 hembras y 02 machos, de edades no determinadas, ya que habían sido importados sin sus registros. Debido a la poliestricidad, el empadre se dio en forma libre y permanente.

La alimentación fue al pastoreo rotativo en pastos cultivados y naturales; la suplementación fue esporádica, principalmente en la época de sequía, con una mezcla de maíz, polvillo, sal común y sales minerales.

El destete se dio también en forma natural, lo cual ocurría por lo general a partir de los 3 meses. Para la toma de datos se elaboraron planillas y formatos adecuados, en los que se registraban las pariciones, fechas de nacimiento, pesos al nacer, etc. La identificación de crías se realizó mediante tatuajes en la oreja izquierda, con numeración ascendente: impares para machos y pares para hembras.

Los caracteres reproductivos que se registraron fueron entre otros, los siguientes: fertilidad, duración de gestación, intervalo entre partos, tamaño de carnada, prolificidad, mortalidad, etc.

Los caracteres productivos que se registraron fueron: peso al nacimiento, destete al año, ganancia de peso diario, peso y edad a la madurez sexual, edad a la primera parición, etc.

\section{RESULTADOS}

\section{1 Caracteres reproductivos}

\subsubsection{Precocidad}

La evaluación se realizó en 21 borreguillas, provenientes de 9 partos dobles y 12 partos simples, todas ellas nacidas en el plantel del IIAP-CEDEGA, entre los años 1987- 1989. En el Cuadro $\mathrm{N} \cong$ 1, se observa el promedio de edad a la primera fecundación, así como la edad promedio al primer parto. 


\section{CUADRO № 01}

EDAD Y PESOS AL PRIMER PARTO EN BORREGUILLAS PELIBUEY PARUANAS

\begin{tabular}{|c|c|c|c|c|}
\hline $\begin{array}{c}\text { EDAD PRIMERA } \\
\text { FECUNDACION }\end{array}$ & EDAD AL PRIMER & PESO AL PRIMER & \multicolumn{2}{|c|}{ \% TIPO PARTO } \\
\cline { 4 - 5 } & PARTO & PAMTO & SIM PLE & DOBLE \\
\hline 325 días & 474 dias & $29.57 \mathrm{Kg}$ & 57.14 & 42.86 \\
10.8 meses & 15.8 meses & & & \\
\hline
\end{tabular}

\subsubsection{Prolificidad}

Se ha tomado en cuenta las épocas de parición por cada año, tanto para partos simples como dobles, habiéndose evaluando un total de partos en el período agosto 1987- agosto 1990.

\section{CUADRO № 2}

\section{TIPOS DE PARTOS Y PROLIFERACION POR EPOCA DE PARICION (AGOSTO 1987- AGOSTO 1990)}

\begin{tabular}{|c|c|c|c|c|c|c|c|c|c|}
\hline \multirow[t]{2}{*}{$\begin{array}{c}\text { EPOCAS } \\
\text { DE PARICION }\end{array}$} & \multirow{2}{*}{$\begin{array}{l}\text { No VIENTRES } \\
\text { EN EMPAQUE } \\
\text { CONTINUO }\end{array}$} & \multicolumn{3}{|c|}{ TIPOS DE PARTO } & \multicolumn{3}{|c|}{$\begin{array}{c}\% \text { POR TIPO DE } \\
\text { PARTO }\end{array}$} & \multirow{2}{*}{$\begin{array}{c}N \underline{0} \\
\text { CORDERO } \\
\text { S } \\
\text { NACIDOS }\end{array}$} & \multirow{2}{*}{$\begin{array}{l}\text { PRO- } \\
\text { LIFICI- } \\
\text { DAD }\end{array}$} \\
\hline & & $S$ & $\mathrm{D}$ & $T$ & $S$ & $\mathrm{D}$ & $T$ & & \\
\hline AGO- NOV 87 & 30 & 20 & 06 & - & 77 & 23 & - & 32 & 1.23 \\
\hline MAR-JUN 88 & 26 & 12 & 07 & - & 63.2 & 36.8 & - & 26 & 1.37 \\
\hline AGO-NOV 88 & 31 & 12 & 14 & 01 & 44.4 & 51.9 & 3.6 & 43 & 1.59 \\
\hline MAR-MAY 89 & 24 & 11 & 07 & - & 61.1 & 38.9 & - & 25 & 1.39 \\
\hline AGO-NOV 89 & 25 & 10 & 07 & - & 58.8 & 41.2 & - & 24 & 1.41 \\
\hline MAR-AGO 90 & 30 & 20 & 08 & - & 71.5 & 28.5 & - & 36 & 1.28 \\
\hline SUB TOTAL & & 85 & 49 & 01 & & & & & \\
\hline & & & 135 & & & 100 & & 186 & 139 \\
\hline
\end{tabular}

\subsubsection{Mortalidad}

Del total de 186 corderitos nacidos entre agosto de 1987 y agosto de 1989 , se ha registrado una mortalidad total de $24.8(\%)$, de acuerdo al siguiente detalle por épocas de pariciones (cuadro $N o 3$ ). 


\section{CUADRON23}

MORTALIDAD POR TIPO DE PARTO

\begin{tabular}{|c|c|c|c|c|c|c|c|}
\hline \multirow{2}{*}{$\begin{array}{c}\text { EPOCAS } \\
\text { DE }\end{array}$} & \multicolumn{3}{|c|}{$\begin{array}{c}\text { MORTALIDAD POR TIPO } \\
\text { DE PARTO }\end{array}$} & \multicolumn{3}{c|}{$\begin{array}{c}\text { \% MORTALIDAD POR TIPO } \\
\text { DE PARTO }\end{array}$} & \multirow{2}{*}{ TOTAL } \\
\cline { 2 - 6 } PARICION & SIMPL & DOBL & TRIPL & SIMPL & DOBL & TRIPL & \\
\hline AGO-NOV 88 & 04 & 08 & - & 12.5 & 25.0 & - & $37.5\left(^{*}\right)$ \\
MAR-JUN 88 & 01 & - & - & 3.8 & - & - & 3.8 \\
AGO-NOV 88 & - & 05 & 03 & - & 11.6 & 7.0 & 18.6 \\
MAR-MAY 89 & 03 & 11 & - & 12.0 & 44.0 & - & 56.0()$\left.^{*}\right)$ \\
AGO-NOV 89 & 01 & 01 & - & 4.2 & 4.1 & - & 8.3 \\
MAR-AGO 90 & 03 & 06 & - & 16.6 & 8.3 & - & $24.9\left(^{*}\right)$ \\
\hline \multicolumn{9}{|c|}{} \\
\hline
\end{tabular}

(") Las mortalidades altas fueron resultadode fuertes problemas defotosensibilización, presentados en crías antes del destete.

\subsubsection{Intervalo entre partos}

De un total de 79 partos entre 1988 y 1990, se aprecia un intervalo de partos promedio de 236.4 \pm 41.3 días (Cuadro $\mathrm{N}^{2} 4$ ).

\section{CUADRO N²}

INTERVALO ENTRE PARTOS

\begin{tabular}{|c|c|c|c|}
\hline AÑO & EPOCA & Ne PARTOS & I.P (días) \\
\hline 1987 & --- & -- &..-- \\
1988 & Marzo-Junio & 19 & $220.7 \pm 14.3$ \\
1988 & Agosto-Noviembre & 20 & $214.3 \pm 56.6$ \\
1989 & Marzo-Mayo & 13 & $197.3 \pm 13.2$ \\
1989 & Agosto-Noviembre & 14 & $231.9 \pm 59.5$ \\
1990 & Marzo-Agosto & 13 & $300.1 \pm 63.1$ \\
\hline \multicolumn{2}{|c|}{ PERIODO AGOSTO 1987-AGOSTO 1990 } & 79 & $236.4 \pm 41.3$ \\
\hline
\end{tabular}

\subsubsection{Ciclo estral}

Para la toma de datos se han evaluado 30 ovejas, lascuales han arrojado los siguientes resultados, entre celo y celo (Cuadro $\mathrm{N}^{2} 5$ ). 
CUADRO N²5

CICLO ESTRIAL

\begin{tabular}{|c|c|c|}
\hline N $^{2}$ ANIMALES & CICLO ESTRAL (días) & $\%$ \\
\hline 02 & 15 & 6.7 \\
03 & 16 & 10.0 \\
15 & 17 & 50.0 \\
06 & 18 & 20.0 \\
03 & 19 & 10.0 \\
01 & 20 & 3.3 \\
\hline TT $=30$ & $\bar{x} 17.27 \pm 1.11$ & $100.0 \%$ \\
\hline
\end{tabular}

3.1.6 Gestación

Para la evaluación de la gestación se han estudiado 40 ovejas, tanto de las Pelibuey cubanas como Pelibuey nacidas en el plantel, arrojando los resultados siguientes (Cuadro $\mathrm{N}^{2} 6$ ).

CUADRO N6

GESTACION

\begin{tabular}{|c|c|c|}
\hline N $^{2}$ ANIMALES & GESTACION (días) & $\%$ \\
\hline 01 & 144 & 2.5 \\
02 & 146 & 5.0 \\
03 & 147 & 7.5 \\
07 & 148 & 17.5 \\
11 & 149 & 27.5 \\
09 & 150 & 22.5 \\
03 & 151 & 7.5 \\
02 & 153 & 5.0 \\
01 & 157 & 2.5 \\
01 & 158 & 2.5 \\
\hline TT $=40$ & $\overline{\mathbf{x}}=149.4 \pm 2.5$ & $100.0 \%$ \\
\hline
\end{tabular}

\subsection{Parámetros productivos}

3.2.1. Pesos al nacimiento por tipo y sexo

Se evaluaron 178 nacimientos, arrojando los siguientes resultados (Cuadro $\mathrm{N}^{2} 7$ ).

\section{CUADRO N 7}

PESOS AL NACIMIENTOS POR TIPO Y SEXO

\begin{tabular}{|c|c|c|c|c|c|c|}
\hline \multirow{2}{*}{ TIPO } & \multicolumn{2}{|c|}{ CORDEROS HEMBRAS } & \multicolumn{2}{c|}{ CORDEROS MACHOS } & \multicolumn{2}{c|}{ TOTAL } \\
\cline { 2 - 7 } NACIMIENTO & $\mathrm{N}^{e}$ & $\mathrm{x}$ & $\mathrm{N}^{\mathrm{N}}$ & & $\mathrm{N}^{\circ}$ & $\mathrm{x}$ \\
\hline SIMPLE & 43 & $2.74 \pm 0.55$ & 42 & $3.20 \pm 0.50$ & 85 & $2.97 \pm 0.52$ \\
DOBLE & 43 & $2.55 \pm 0.38$ & 50 & $2.57 \pm 0.36$ & 93 & $2.56 \pm 0.37$ \\
\hline TOTAL & 86 & $2.64 \pm 0.46$ & 92 & $2.88 \pm 0.43$ & 178 & $2.76 \pm 0.44$ \\
\hline
\end{tabular}


CUADRO N 8

PESO AL NACIMIENTO POR EPOCA DE PARICION Y SEXO

\begin{tabular}{|c|l|l|c|c|c|c|c|}
\hline \multirow{2}{*}{ ANNO } & \multirow{2}{*}{$\begin{array}{c}\text { EPOCA } \\
\text { DE } \\
\text { PARICION }\end{array}$} & \multicolumn{2}{|c|}{ COREROS HEMBRAS } & \multicolumn{2}{c|}{ CORDEROS MACHOS } & \multicolumn{2}{c|}{ TO TAL } \\
\cline { 3 - 8 } & Ne & $\mathrm{N}$ & $\mathrm{N}^{2}$ & & $\mathrm{~N}^{2}$ & $\mathrm{x}$ \\
\hline 1987 & AGO-NOV. & 18 & $2.63 \pm 0.53$ & 11 & $3.03 \pm 0.43$ & 29 & $2.78 \pm 0.53$ \\
1988 & MAR-JUN. & 15 & $2.50 \pm 0.57$ & 11 & $2.84 \pm 0.47$ & 26 & $2.64 \pm 0.55$ \\
1988 & AGO-NOV. & 23 & $2.57 \pm 0.53$ & 17 & $2.58 \pm 0.54$ & 40 & $2.57 \pm 0.52$ \\
1989 & MAR-MAY. & 09 & $2.17 \pm 0.39$ & 15 & $2.71 \pm 0.54$ & 24 & $2.51 \pm 0.55$ \\
1989 & AGO-NOV. & 08 & $2.74 \pm 0.53$ & 15 & $2.81 \pm 0.55$ & 23 & $2.78 \pm 0.53$ \\
1990 & MAR-AGO & 13 & $2.75 \pm 0.42$ & 23 & $2.95 \pm 0.41$ & 36 & $2.85 \pm 0.41$ \\
& AG. 87-AG. 90 & 86 & $2.56 \pm 0.49$ & 92 & $2.82 \pm 0.49$ & 178 & $2.69 \pm 0.49$ \\
\hline
\end{tabular}

CUADRO NE 9

PESOS A LOS 90 DIAS POR TIPO DE PARTO Y SEXO (Kg)

\begin{tabular}{|c|c|c|c|c|c|c|}
\hline \multirow{2}{*}{ TIPO } & \multicolumn{2}{|c|}{ CORDEROS HEMBRAS } & \multicolumn{2}{|c|}{ CORDEROS MACHOS } & \multicolumn{2}{c|}{ TOTAL } \\
\cline { 2 - 7 } NACIMIENTO & $\mathrm{N}^{2}$ & $\mathrm{x}$ & $\mathrm{N}^{2}$ & $\mathrm{x}$ & $\mathrm{N}^{2}$ & $\mathbf{x}$ \\
\hline SIMPLE & 23 & $15.32 \pm 2.44$ & 21 & $3.20 \pm 0.50$ & 44 & $15.35 \pm 2.24$ \\
DOBLE & 22 & $12.30 \pm 2.15$ & 13 & $2.57 \pm 0.36$ & 35 & $12.48 \pm 1.90$ \\
\hline TOTAL & 45 & $13.81 \pm 2.29$ & 34 & $2.88 \pm 0.43$ & 79 & $13.92 \pm 2.07$ \\
\hline
\end{tabular}

CUADRO $N^{2} 10$

PESOS A LOS 90 DIAS POR EPOCA DE PARICION Y SEXO

\begin{tabular}{|c|c|c|c|c|c|c|c|}
\hline \multirow{2}{*}{ ANNO } & \multirow{2}{*}{$\begin{array}{c}\text { EPOCA } \\
\text { DE } \\
\end{array}$} & \multicolumn{2}{|c|}{ CORDEROS HEMBRAS } & \multicolumn{2}{c|}{ CORDEROS MACHOS } & \multicolumn{2}{|c|}{ TO TAL } \\
\cline { 3 - 8 } & PARICION & $\mathrm{N}^{0}$ & $\mathrm{x}$ & $\mathrm{N}$ & $\mathrm{x}$ & $\mathrm{N}^{2}$ & $\mathrm{x}$ \\
\hline 1987 & AGO-NOV. & 16 & $15.26 \pm 2.39$ & 06 & $17.7 \pm 2.56$ & 22 & $15.92 \pm 2.62$ \\
1988 & MAR-JUN. & 14 & $12.58 \pm 2.68$ & 11 & $15.01 \pm 3.29$ & 25 & $13.65 \pm 3.15$ \\
1988 & AGO-NOV. & 05 & $14.27 \pm 2.49$ & 05 & $12.66 \pm 1.1$ & 10 & $13.43 \pm 1.99$ \\
1989 & MAR-MAY & 04 & $11.87 \pm 1.97$ & 06 & $12.82 \pm 1.99$ & 10 & $12.44 \pm 1.93$ \\
1989 & AGO-NOV. & 06 & $14.73 \pm 2.73$ & 05 & $14.86 \pm 3.15$ & 11 & $14.79 \pm 2.75$ \\
1990 & MAR-AGO & 02 & $12.35 \pm 0.35$ & 04 & $14.0 \pm 3.0$ & 06 & $14.0 \pm 3.00$ \\
\hline
\end{tabular}




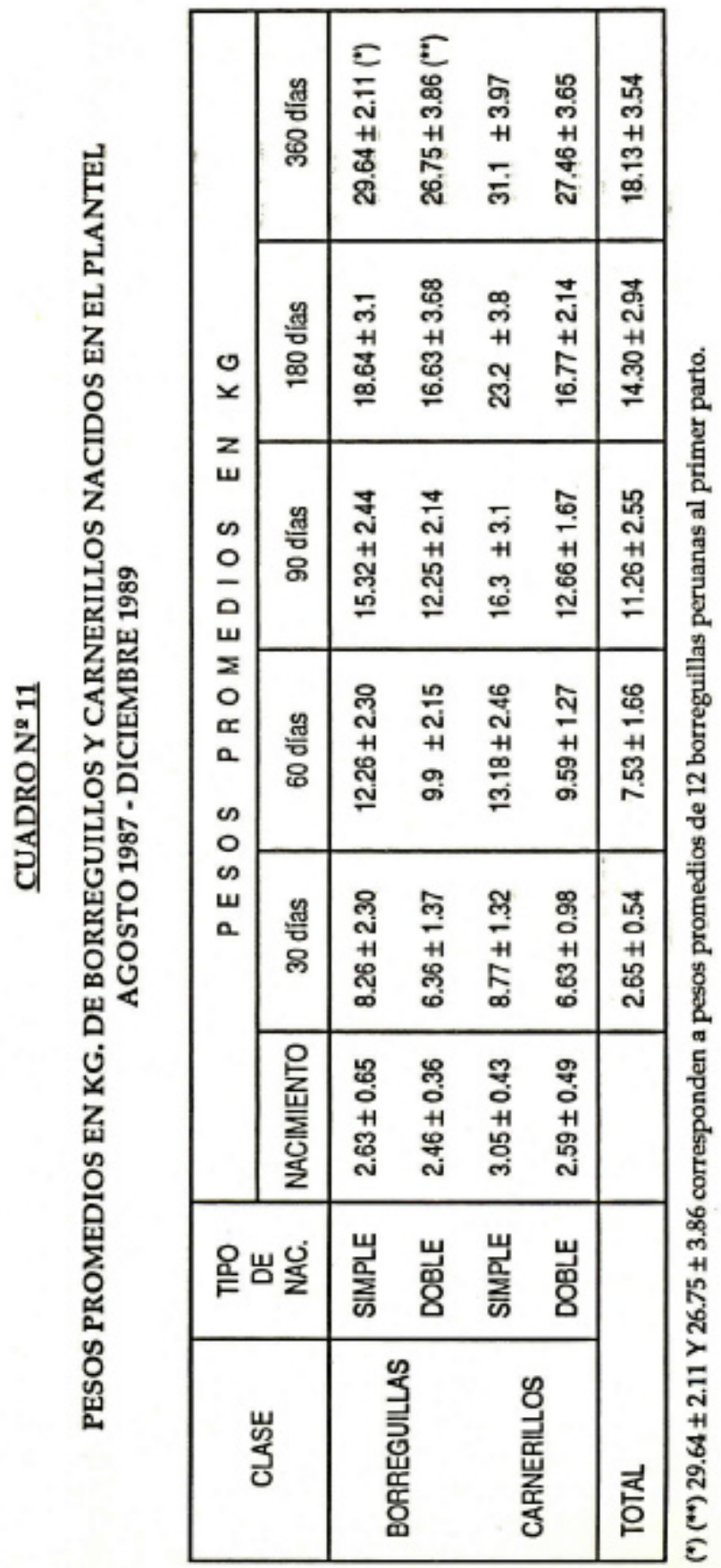




\section{DISCUSION}

\subsection{En relación a la precocidad}

Es deseable que las actividades reproductivas se inicien en forma temprana, las ovejas Pelibuey, nacidas en el plantel que se evaluó, han manifestado el primer celo a partir de los 240 días de su nacimiento (8 meses). Se observó una media de 10.8 meses ( 325 días), con lo cual las edades al primer parto se producían a partir de los 12.8 meses, con una media de 1.58 meses (474 días); cabe manifestar que, en relación a la precocidad, ésta, en varios casos, se ha visto afectada por la fotosensibilización, la que al afectar a las ovejas retardaba su crecimiento y desarrollo. Las ovejas que no fueron afectadas por la fotosensibilización tuvieron, por lo general, su primer parto alrededor de los trece meses.

Estos datos se encuentran en los reportados por Fuentes et al (1983), quien afirma que en las épocas de lluvias y mejores pastos se observa ganancia de peso de las crías. Este efecto nutricional en las crías, antes del destete y durante el post destete, regula el período de entrada a la pubertad y el primer parto; asimismo, menciona que las edades primer parto en ovejas Pelibuey fueron de 14.5, 15.2, 16.2 y 14.0 meses para las borregillas nacidas en primavera, verano, otoño e invierno. Se aprecia también, que los pesos de las borreguillas al primer parto estuvieron alrededor de los $30 \mathrm{~kg}$, tanto en partos dobles como simples.

Hay una ligera variación en lo referente a la edad al primer parto entre borreguillas que provienen de partos dobles y simples; en los provenientes de partos simples, las edades al primer parto son menores de las que provienen de partos dobles, esto podría deberse a que las borreguillas de partos simples nacen con mayores pesos, lo que les permite incrementar su peso con mayor rapidez y llegar con buen peso a la madurez sexual en menor tiempo. En general, las edades al primer parto obtenidas son menores que en sus lugares de origen.

\subsection{En relación a la prolificidad}

La prolificidad obtenida ha variado según la época de parición entre 1.23 y 1.59 , con una media de 1.39 , la que se asemeja a la reportada por Fuentes et al (83), pero superior a las reportadas en M éxico por Castillo et al (72), V alencia y Gonzáles (83).

La proliflcidad de las ovejas Pelibuey es menor a las reportadas para Blackbelly, pero mayores a las del tipo Sta. Inés.

Se ha observado que la proliflcidad es influenciada por una buena alimentación y provisión de sales minerales, siendo más alta en las pariciones que se dan entre agosto y diciembre; ésto es debido a que las ovejas se empadran cuando existe buena disponibilidad de pastos (marzo - abril - mayo junio y julio). Se aprecia, asimismo, que la mayor 
provisión de suplemento alimenticio se les proporciona durante los meses de sequía (junio - setiembre).

\subsection{En relación a la mortalidad}

L a mortalidad general de $24.8 \%$ en crías entre I y 6 meses se debe a los constantes problemas de fotosensibilización que se presentaba, al ser mantenidos sobre un piso forrajero constituido principalmente por Brachiaria sp. El porcentaje de mortalidad por causa de otras enfermedades y accidentes ha sido muy reducida, aproximadamente $6 \%$, de lo que se deduce que de no haber tenido el problema de fotosensibilización, el porcentaje de mortalidad sería muy inferior a los reportados en otros países.

\subsection{En relación al intervalo entre partos}

El lapso entre un parto y el servicio afecta la eficiencia reproductiva, siendo un intervalo óptimo para el primer servicio después del parto entre 45 y 60 días. Valencia y Gonzáles (83), reportan una fertilidad de $63 \%$ y un intervalo entre partos y servicio de 45 a 75 dias, pero cuando se incrementa el intervalo entre partos la fertilidad aumenta.

$V$ ariaciones entre 45y7S días han sido reportadas para el intervalo parto - primer servicio, Sham y Tiwari (77). En el plantel experimental de 79 partos evaluados se ha obtenido un promedio de $236.4 \pm 41.3$ días para el intervalo entre parto y parto y con un intervalo entre parto y servicio de 86 días, el cual es ligeramente superiora los reportados en Cuba, pero similares a los reportados en M éxico.

\subsection{En relación al ciclo mestrual}

Las verificaciones se llevaron a cabo en 30 ovejas, arrojando un promedio de $17.27 \pm 1.11$; las evaluaciones se efectuaron con el retorno del astro, cuando no se producía la fecundación en el primer celo. Estos resultados se encuadran en los parámetros normales. Devendra y Leroy (1986), reportan que en las ovejas tropicales el ciclo se repite entre 15 a 19 días, mientras en el plantel se han producido celos entre 15 a 20 días, resultados que también se han dado en ovejas Blackbelly, en Iscozacín, Basualdo (1987).

\subsection{En relación a la gestación}

Se obtuvo un promedio de duración de la gestación de $149.4 \pm 2.5$ días, habiéndose evaluado un total de 40 ovejas; las variaciones entre tipos de partos no fueron significativas, por lo que se consigna datos promedios en general.

Los datos obtenidos son similares a los conseguidos por Basualdo, en Iscozasin, con ovejas Blackbelly; Rodríguez, en Iquitos, con ovejas Sta. 
Inés, Valencia y Gonzáles (1983), con ovejas Pelibuey, en M éxico (149.5, 149.3 y 148. 9 días).

Al igual que en Iquitos e Iscozacin, el período de gestación en ovejas que producen partos simples es ligeramente superior al de dobles y triples; esto podría deberse a la mayor carga fetal de los partos dobles y triples.

\subsection{En relación a los pesos al nacimiento (C uadros № 7 y 8)}

Los pesos obtenidos en promedio general son $2.76 \pm 0.44$; se evaluaron un total de 178 nacimientos, el promedio para hembras fue $2.64 \pm 0.46$ (86 crías) y para machos $2.88 \pm 0.43$ (92 crías).

Estos pesos son ligeramente superiores a los reportados por Basualdo, en Iscozacín (1987); asimismo, inferiores a los reportados por Fuentes et al (1983), superiores a los reportados por Combellas (1980), menores a los reportados para Sta. Inés, en Brasil, pero ligeramente superiores a los registrados para Sta. Inés en Iquitos.

En general, se puede decir que los pesos obtenidos, tanto en partos dobles y simples, ya sean hembras o machos, están en los parámetros correspondientes a los ovinos tropicales; las diferencias que existen se deben a los diferentes niveles de alimentaciones que tuvieron las ovejas madres durante las épocas de empadre y gestación.

\subsection{Pesos al destete (C uadros № 10 y 11)}

Sobre un total de 79 animales evaluados, se obtuvo un promedio general de $13.92 \pm 2.07 \mathrm{~kg}$. De peso al destete (90 días); al respecto, se observa que no existió diferencia significativa entre los provenientes de partos simples 0 dobles. Cabe mencionar que los mejores pesos se lograron en 1987 (parición agosto - noviembre), época en que las ovejas y crías estuvieron mejor alimentadas, por existir mayor disponibilidad de pastos, ya que la carga $\mathrm{V} .0 / \mathrm{H}$ a en esa época era menor a la existente en años posteriores. Esto demuestra que estos parámetros pueden ser sustancialmente mejorados en base a un manejo adecuado.

Se evidencia así que los pesos obtenidos son mayores a los logrados en su lugar de origen, Cuba y M éxico; asimismo, son superiores a los reportados por Rodríguez, en Iquitos, con ovinos Sta. Inés.

\section{BIBLIOGRAFIA}

1. BASUALDO, R.P. 1987. Evaluación reproductiva de ovinos Black Belly en Barbados, en condiciones de la Selva Central del Perú. Tesis UNALM . 162p. Lima.

2. BRADFORD Y FITZHUGH, 1973, Hair sheep. A general description en "Hair sheep of western A frica and the A mericas, A genetic resource br the tropics. 
3. COMBELLAS, J.B. 1979. Comportamiento de ovejas tropicales y sus cruces en un sistema de producción intensiva UCV. (UNIVERSIDAD CENTRAL DE VENEZUELA).

4. FUENTES; J.L; LIMA. T; PULE VOTS; N.M.; ALBUERNES; R, San V., Pavón, M., Perón, N. 1983 a, Algunas consideraciones de la actividad reproductiva de la oveja Pelibuey en Cuba. Colloque " $L$ a reproduction des rumiants en zona tropical" Guadaloupe, 8-10 juin 1983. INRA CRAAG.

5. GONZALES, S.C, 1985 - Crianza y producción de las ovejas tropicales. Quito Ecuador.

6. RODRIGUEZ, L.S. 1987. Informe técnico final del Proyecto investigación del comportamiento productivo y reproductivo de ovinos de pelo en trópico húmedo. IIAP - Iquitos.

7. TIWARI, S.B.; SAHNI, K.L. 1975. Indian J. A nim Sei 45-351.

8. VALENCIA, M., CASTILLO, R.H. BERRUECOS, V.M. 1975. Reproducción y manejo de borrega Tabasco o Pelibuey Téc. Pecuaria. M éxico. 